\title{
OPEN
}

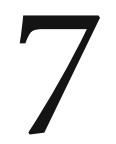

\section{National Libraries and Academic Books of the Future}

\author{
Maja Maricevic
}

\begin{abstract}
In the near future, national libraries could adopt new roles within the national research infrastructure, such as policy co-ordination, development of national and international interoperability standards, and improving the discovery of academic books, in addition to their traditional roles in ensuring long-term access and preservation. Equally, the complexity and resource-intensive nature of these changes, combined with the rising budgetary pressures faced by libraries, will mean that the future role of national libraries in scholarly ecosystems will depend on their capability to innovate and to transform their relationships with researchers, universities and research funders. This chapter considers some generic trends that might influence how national libraries engage with a growing debate about the future of academic books.
\end{abstract}

Keywords: academic book; British Library; librarianship; monograph; national libraries; Open Access; preservation; research policy; scholarly communications

Lyons, Rebecca E. and Samantha J. Rayner (eds). The Academic Book of the Future. Basingstoke: Palgrave Macmillan, 2016. DOI: 10.1057/9781137595775.0014. 
National libraries provide essential research infrastructure for arts and humanities and social science researchers; they are national centres for academic books. Their traditional role of providing a systemic collection of national publications, in most cases supported by legal deposit (which in some instances has been in operation for centuries), creates comprehensive repositories of academic books past and present.

For many disciplines, national libraries offer an additional advantage of providing unique primary research sources, and significant international collections complementing a continuum of national academic publications. In such an immersive research environment, arts and humanities academic researchers in particular tend to become more than readers, and often develop a deep interest in, and understanding of, how national libraries acquire, provide access to and preserve their collections. In many cases national libraries' collections are seen as a resource integral to the future of their research. Some researchers spend many years investigating specific, often unique collections, while others expect national libraries to provide comprehensive resources for their discipline. ${ }^{1}$

Digital changes to date have not altered the essence of this close relationship between national libraries, researchers, and academic books. However, if academic books are changing, will this well-established relationship change in the process? Will national libraries become vast digital platforms, where the researchers of tomorrow can remotely manipulate text, data, and multimedia, producing new knowledge through digitally enabled collaborations? Or maybe such digital platforms will be created outside national libraries, emulating model of disciplinary repositories in sciences? ${ }^{2}$

It is difficult to tell if such integrated digital platforms will be appropriate to support arts and humanities research in the future. However, some present developments can help us to examine how national libraries, researchers, and academic books may relate to each other in the future.

Discussions about whether Open Access will be made mandatory for academic books by research funders are a useful starting point in examining how academic books might develop. ${ }^{3}$ It is often in this context that we see most clearly that academic books are changing. Open Access debate has reinvigorated scholarly examination of research information policy and publication models in the arts and humanities. ${ }^{4}$ The growing interest in Open Access has also led to experimentation with new acquisition, publication and dissemination models for academic books 
through pioneering projects such as OAPEN, ${ }^{5}$ Knowledge Unlatched ${ }^{6}$ and the emerging Open Library of Humanities. ${ }^{7}$

This does not mean that all changes in the academic book environment should be attributed to Open Access. A great deal of change is arising due to changes in researchers' reading and information-seeking behaviours as they take advantage of the pervasive convenience, immediacy, and speed of digital information environment.

In 2012 The British Library and Jisc completed a three-year longitudinal study of doctoral students, which followed a large cohort of 3,00o doctoral students and offered many insights into their research behaviours. For example, young researchers in the arts and humanities perceived ejournals as slightly more important than academic books, with nearly 30 per cent using Google as their main channel to find all resources they need. ${ }^{8}$

Another driver of change comes from the nature of academic books as a research output, alongside journal articles and data, which means that in order to remain relevant, academic books will most likely need to be 'rewired' to fit the same or similar research assessment environments, and to achieve wider and measurable impact through digital channels.

While we want to hold onto the distinctiveness of research communications in the arts and humanities, and especially acknowledge the unique role of monographs and other long-form publications, ${ }^{9}$ we also need to acknowledge that some of the change drivers for academic books are similar to what we have already seen in the science, technical and medical (STM) publication environment. It makes sense therefore that we take a hard look at the changes that have taken place in STM and find out what can be learnt by all interested in academic books, including national libraries.

Looking at a recent report published by STM, the leading global trade association for academic and professional publishers, we see that technological innovation related to final publications is modest - it is usually a PDF of an article. However, there are significant levels of business process change - new aggregation models, new Open Access publication models, even new models of peer review. Another striking feature of STM publishing is the centrality of funders' mandates. ${ }^{10}$ In this context, national libraries are acknowledged for their preservation role, and are placed alongside commercial preservation solutions such as CLOCSS/ LOCKSS and PORTICO. ${ }^{11}$ Significantly for this discussion, the report concludes that there is 'a growing focus on the researcher (as opposed 
to the library), driven partly by the redefining of the customer in the OA model, but also by a focus on research assessment and metrics.' ${ }^{12}$

From the perspective of the national libraries, if academic books in the arts and humanities become more like ejournals, this would mean shifts in the expectations of arts and humanities researchers, including an expectation of universal remote paywall-free access for academic books.

The majority of academic books find their way into national libraries via legal deposit. In a digital environment, legal deposit for non-print works still makes this possible and it provides a long-term preservation solution for academic books, but it does not satisfy the researchers' growing need for immediate, remote access to digital resources. ${ }^{13}$ Such access has to be provided through different mechanisms.

Typically, the access options can be extended by purchasing relevant subscriptions or through linking to Open Access resources, but both of these options require national libraries to find additional resources at the time of ongoing budget cuts for libraries in many countries. As funding becomes more constrained, it becomes harder for national libraries to make a case for required investments in scholarly publications, while also developing their capability to manage the multitude of other digital publications - non-academic ebooks, online newspapers, growing audio and video collections, web archives, and digitised heritage collections. For many of these collections national libraries may be the only home, while the higher education sector has a well-developed library infrastructure and possibly a greater incentive to invest in academic digital resources. In today's resource-constrained environment, it could be argued that arts and humanities research would be better served by national libraries if they focused more on digital collections outside scholarly publishing, which are also essential in arts and humanities research.

Following and adjusting to the complexity of changes in research environments is an expensive and resource-demanding undertaking. Changes in scholarly communications are usually bespoke and follow the rules of research process as much as that of digital publication. Understanding this changing environment means constantly maintaining and growing the capacity to understand academic research, which requires appropriate funding and expertise. National libraries aiming to remain a relevant home for academic books in the future need to consider both their appetite and readiness to meet the changes 
taking place in arts and humanities research and academic books publication.

We should not be surprised if, under these conditions, a legitimate outcome for national libraries becomes less of a focus on academic books. Inevitably this will mean that the role of the national library as an integrated arts and humanities research ecosystem could be altered and reduced, which is why it is much more likely that national libraries will want to continue their long involvement with academic books - including both their preservation and improving access for researchers. This will be even more likely if it is clear that this continues to be important to researchers in arts and humanities.

The British Library holds 14.7 million monographs, and in 2013/14 alone added 107,554 through legal deposit. ${ }^{14}$ For this collection to grow and to remain relevant in the future, it is essential for the British Library to understand and anticipate the changes in the academic publishing environment and to work closely with others to meet the challenges of rising costs and the increasing complexity of digital processes.

On this journey it will be essential for national libraries to strengthen relationships with the parts of government that have responsibility for research policy and research funding. Again, looking at the Open Access developments to date, ${ }^{15}$ it is noticeable that national libraries play a more prominent role in the Open Access implementation in those countries where there are strong links between research funders and national libraries. A description of such a relationship in Sweden paints a picture of a national library as 'a catalyst for a closer cooperation between the main bodies of research and research libraries in advancing an open access agenda and developing a digital research information infrastructure.16

This points to another key set of relationships that needs to be in place, with academic libraries more generally. In the UK a key document describing the need for closer collaboration of policy-makers, academic libraries, and national libraries is A National Monograph Strategy published in 2014. It is interesting that this document recognises the need for collaboration in the digital environment, but it also highlights the need for collaborating in improving management of existing physical collections, which is important if the future arts and humanities publication landscape is to retain physical books. ${ }^{17}$

One of the most significant alliances with academic libraries should be around the common understanding of the importance of digital 
preservation. For instance, recent research undertaken in academic libraries and repositories shows the difficulties that they face in maintaining, preserving, and providing long-term access to ebook collections. ${ }^{18}$ It is an additional reason why preservation of academic books should remain at the centre of future considerations in national libraries.

The British Library worked with the Research Councils UK and the Global Research Council in April 2015 to examine the current status of policy and practice in Open Access communications. This forum reported the following in relation to preservation:

Libraries can play a key role here: the current system of legal deposit libraries is effective in picking up most research to be curated and preserved for the long-term. This is a mix of physical and digital at the moment, but is moving towards predominantly digital deposit. However, as the legal deposit system only picks up published material in each national domain that has such provision, we need to think about new models of long-term archiving and preservation for OA materials that are being made available outside traditional publishing. ${ }^{19}$

While the national libraries' eye on future preservation issues is essential, it is also important that they experiment with emerging possibilities for access and use of digital scholarly content. If the academic book of the future becomes a flexible, engaging digital object, this may enable national libraries to provide new services not only to academic researchers, but also to their public and business audiences. The most effective way of finding what these future uses might look like is by allowing room for experimentation.

One such experiment is the recent $\mathrm{BL} \mathrm{Lab}{ }^{20}$ project, which digitally 'cut out' one million images from nineteenth-century books, mostly monographs, and placed them on Flickr. To date these images have been viewed 271 million times and the public has added 422,00o tags to these images. In the process, the British Library learned a lot about crowdsourcing and about the potential for re-use of book images and illustrations. ${ }^{21}$ Another such activity was producing the British Library's first MOOC in collaboration with the University of Nottingham - Propaganda and Ideology in Everyday Life. This digital course contains a series of videos, texts, collection show-and-tells, and interactive discussions. Would the academic book of the future be doing something similar? Will it become a collection of different digital elements combined to expound a longform academic argument? 
We do not know yet. However, a national library that is open to exploring these new formats will be in a better place to consider changing formats of publication in the future. The British Library's collaboration with the AHRC to develop the research call for The Academic Book of the Future project, and its subsequent work with the project research team and other stakeholders encapsulates what might be needed right now: a research funder and a national library collaborating to find new insights from research communities, and in the process engaging with wider researcher communities, libraries, and publishers to discuss issues that we have hitherto been considering separately from each other.

The present moment offers an exciting environment for experimentation, for building new and deepening existing relationships, which in turn may lead to a common understanding of what we want the academic books of the future to do - if we want them to be different, in which ways, and to what purpose.

\section{Notes}

1 In December 2011 The British Library surveyed nearly 3,00o academic researchers of whom 43.8 per cent said that they would have not achieved all their research aims without The British Library's collections. These researchers rated highly The British Library's capability to provide both the breadth and depth of content that supports their research across a wide range of disciplines. The survey data has not been published. Few respondents' views (Shelagh Rowan-Legg, Diana Newall and Alex Hall) were recorded for the Made with the British Library campaign: http://www.bl.uk/made-with-thebritish-library, accessed 5 September 2015.

2 PubMed http://www.ncbi.nlm.nih.gov/pubmed and Europe PubMed Central https://europepmc.org - disciplinary repositories and discovery platforms that bring together biomedical literature including life science journals and online books, accessed 5 September 2015.

3 The majority of public research funders in Europe and around the world, as well as an increasing number of independent and charity research funders, now mandate that the outputs of research that they fund should be made available free of charge to end users, with the cost being met elsewhere in the publication process. The majority of such mandates focus on journals and do not include academic books, but this remains a developing agenda. The future mandate for Open Access might include academic books. For example, a recommendation to consider an Open 
Access mandate for scholarly monographs is given in a report produced by Sir Bob Burgess for the Research Councils UK - Review of the Implementation of the RCUK Policy on Open Access (2015): http://www.rcuk.ac.uk/research/ openaccess/2014review/, accessed 10 September 2015.

4 Prominent UK examples include G. Crossick (2014) Monographs and Open Access: A Report to HEFCE, http://www.hefce.ac.uk/media/hefce/content/ pubs/indirreports/2015/Monographs, and,open,access/2014_monographs.pdf, accessed 20 August 2015, and a collection of essays edited by Nigel Vincent and Chris Wickham (2013) Debating Open Access (London: British Academy).

5 See http://www.oapen.org/home, accessed 5 September 2015.

6 See http://www.knowledgeunlatched.org, accessed 5 September 2015.

7 See https://www.openlibhums.org, accessed 5 September 2015.

8 Researchers of Tomorrow: The Research Behaviour of Generation Y Doctoral Students (2012) (London, British Library and Jisc).

9 Crossick, Monographs and Open Access.

10 M. Ware and M. Mabe (2015) The STM Report - An Overview of Scientific and Scholarly Journal Publishing, 4th edn (STM, International Association of Scientific, Technical and Medical Publishers).

11 Ware and Mabe, The STM Report, p. 31.

12 Ware and Mabe, The STM Report, p. 159.

13 In the UK the legal deposit of non-print works allows legal deposit libraries to receive digital publications from the UK for preservation, with some exceptions. They can provide access to this material only in their buildings, and only for one reader at the time. For detail see 'The Legal Deposit Libraries (Non-Print Works) Regulations' (2013) http://www.legislation.gov. uk/uksi/2013/777/pdfs/uksi_20130777_en.pdf, accessed 5 September 2015.

14 'British Library Annual Report and Accounts 2013-14', http://www.bl.uk/ aboutus/annrep/2013to2014/annual-report2013-14.pdf, accessed 10 September 2015.

15 Open Access policies tend to be developed incrementally in order to maintain stability of scholarly communication, control costs and ensure flexibility to adapt to new digital developments. These developments typically include consultative processes with different stakeholders such as research funders, publishers, universities and libraries, including national libraries. In the UK, Universities UK are currently managing such a stakeholder group, monitoring implementation of Open Access policies.

16 J. Hagerlid (2011) 'The Role of the National Library as a Catalyst for an Open Access Agenda: The Experience of Sweden', Interlending and Document Supply, 39(2): 115-18

17 B. Showers (2014) A National Monograph Strategy, http://monographs. jiscinvolve.org/wp/, accessed 10 September 2015. 
18 E. Collins and G. Stone (2014) 'Open Access Monographs and the Role of the Library', Insights - OA Monograph Supplement, 11-16.

19 RCUK (2015) 'Unlocking the Future: Open Access Communication in a Global Research Environment', RCUK website, http://www.rcuk.ac.uk/media/ announcements/150527/, accessed 10 September 2015.

20 See http://labs.bl.uk, accessed 5 September 2015.

21 This British Library blog describes how these images have been used by the Burning Man festival: http://www.bl.uk/events/crossroads-of-curiosity-thebritish-library-meets-burning-man, accessed 5 September 2015.

(c) (i) Except where otherwise noted, this work is licensed under a a copy of this license, visit https://creativecommons.org/version4 